\title{
Reinvestigating the Oil Price-Stock Market Nexus: Evidence from Chinese Industry Stock Returns
}

\begin{abstract}
This paper investigates the influence of international oil prices on China's stock market returns across twenty-nine different industries. It attempts to account for any structural breaks and nonlinearity in this relationship. The results find that the effect of changes in the international price of oil on stock returns differs substantially across industries. The stock returns of the coal, chemicals, mining and oil industries are found to be positively affected by crude oil price movements. Conversely, electronics, food manufacturing, general equipment, pharmaceuticals, retail, rubber and vehicle industries are found to be negatively affected by movements in the price of crude oil. The results of the estimations also suggest that the majority of Chinese industries have been significantly affected by oil prices since 2004. The influence of international oil prices on Chinese stocks was also found to have a stronger effect in the presence of high volatility, but the effect varies across industries.
\end{abstract}

Key words: China’s stock market industries, International oil prices, regime switching, structural break JEL codes: C58, G12, Q48 


\section{Introduction}

Oil is an important commodity and an essential component of a modern industrial economy. This is particularly true for China, the largest developing country in the world. According to China's General Administration of Customs (GAC), the crude oil dependency ratio stood at $65.9 \%$ in 2016. In the first half of 2017, China imported an average of 8.55 million barrels per day, replacing the US as the worlds largest oil importing nation. Energy analysts predict that this trend will continue as China's new urban construction and the Belt and Road Initiatives advance under a new strategy of economic stimulus planned by policymakers. Reforms in China's oil refining industry, which began in the second half of 1998, have strengthened the link between domestic and international oil prices. Therefore, it could be argued that the relationship between international crude oil prices, the Chinese economy and China's financial markets is as strong and as important as ever. With this in mind, studying and understanding the impact of changes in international oil prices on China's economy is of the utmost importance, not only for policy makers in China, but also for prospective investors globally.

Stock prices are influenced by changes in the price of oil through the change in the operating cost of companies and wealth transfer effects (Gogineni, 2010). In addition, the contagion between the oil and stock market occurs due to the financial characteristics of both oil and stock prices. Given these arguments it is clear that, theoretically speaking, changes in the price of international crude oil could bring about significant changes to 
Chinese stock returns. The mechanism that oil price shocks impose on listed companies is not uniform across all industries however. For example, higher oil prices can affect one industry negatively but another positively. Therefore, the impact on stock returns might vary in direction and degree from industry to industry. A key consideration is whether or not crude oil is an essential input for the industry.

We therefore investigates the oil price-stock market relationship in China from 20022015 from the perspective of different stock industries. This paper has a number of novel features. First of all, the impact of oil price changes on industry stock returns is tested for uniformity across industries through a seemingly unrelated regression (SUR) model. Secondly, any nonlinear relationship between the variation in oil prices and China's stock returns is accounted for. The sample period is characterized by a number of important events in the Chinese A-share market such as the split share structure reform in 2005, the 2008 Global Financial Crisis and the recent boom and crash of stock prices in China. These events, along with others, may have caused the relationship between the crude oil market and the Chinese stock market to change over time. By accounting for these changes, it can be determined if the effect of oil price variations on industry returns has switched in any significant way, based for example, on the degree volatility. 


\section{The Effect of Oil Prices on Stock Markets}

The channel by which oil price changes affect the stock market is complex and differs depending on firm performance and the strength of the macroeconomy. There seems to be a consensus that positive shocks to oil prices have negatively depressed macroeconomic activities (Katircioglu et al., 2015), but the effect varies across economies and sectors. Generally speaking, the negative relationship between stock market returns and oil price shocks for oil importing economies has been accepted as a stylized fact (Sadorsky, 1999; Park and Ratti, 2008). Filis et al. (2011) indicate that the relationship between oil prices and stock markets is strongly negative in periods of non-economic crisis, while positive during periods of economic crises or booms. Precautionary demand shocks result in a negative correlation, whereas aggregate demand-side shocks lead to a positive correlation.

The situation may be very different for oil-exporting nations however. Hammoudeh and Choi (2006) display that the oil prices and the S\&P 500 index have no effect on Gulf Cooperation Council (GCC) stock returns. Arouri and Rault (2012) show the existence of a strong and positive long-run relationships between oil prices and stock markets in GCC countries, with the exception of Saudi Arabia. Akoum et al. (2012) on the other hand suggests that oil returns and other stock market returns in the GCC are not strongly correlated in the short term (fluctuations at frequencies between two weeks and six months) but correlated in the long term (fluctuations at frequencies over six months). This 
conclusion is confirmed by Sukcharoen et al. (2014) who suggest a weak and symmetric dependence for the majority of developed and developing nations, with the exception of the US and Canada ${ }^{1}$.

Recent literature has examined the relationship between oil prices and oil-related industries or sectors. For example, both Boyer and Filion (2007) and El-Sharif et al. (2005) investigate the relationship between oil prices and stock returns from oil companies in the Canada and the UK with both finding a positive relationship between the variables. Nandha and Brooks (2009) examine the response of the transportation sector to changes in oil prices in thirty-eight countries and find conflicting results across countries - the authors find that oil prices have a negative influence on transportation sector stock returns in developed countries, but no evidence of a significant role is found in Asia or Latin America. Nandha and Faff (2008) examine the extent of oil price shocks on 35 Datastream global industrial indices for the period April 1983 to September 2005. Their findings suggest that increases in oil prices have an adverse impact on stock returns for all sectors with the exception of mining, oil and gas industries. Meanwhile, their results display a symmetric response of stock market returns to oil prices. This is contrary to the findings of Arouri (2011) who extends the methodology of Nandha and Faff (2008) and finds asymmetry in the relationship between changes in oil prices and industries such as health care, basic materials, personal and household goods \& utilities.

Other studies in the area have begun to focus on the relationship between oil and

1 The authors exclude oil and gas stock companies from the aggregate market indices. 
alternative energy industries. Henriques and Sadorsky (2008) and Kumar et al. (2012), employing a VAR model, conclude that there is a positive relationship between oil prices and alternative energy returns. Managi and Okimoto (2013) add the Markov-switching framework to a recursive structural VAR model in order to account for possible structural breaks in the relationship between oil prices and clean energy stock returns. They find a positive relationship after 2007, before which the positive relationship is not statistically significant.

Despite China’s prominence in the global economy and its ever increasing demand for oil, research on the relationship between oil prices and China's stock market is still relatively scarce. Considering cross-sectional dependence, heterogeneity, and multiple breaks, Li et al. (2012) use panel cointegration to examine the long term relationship between oil prices and the stock indices of 13 different industry sectors in China. Counterintuitively, their findings show that real oil prices have had a positive impact on sectorial stocks in the long run and there is no short-run Granger causality between them. The results also suggest that energy-related stocks are more sensitive to oil price volatility in China's stock market. These arguments are supported by Cong et al. (2008) and Broadstock et al. (2012).

While the literature has dealt with, albeit scarcely, the effect of oil prices on China's stock returns across different sectors, few studies of the structural break in the relationship between oil and Chinese stock markets since the onset of domestic refined oil price reform can be found. There is a distinct lack of research emphasizing the nonlinear relationship 
between oil price and Chinese stock returns across industries. This paper will attempt to examine this relationship by estimating both a breakpoint model and Markov switching (MS) model in the examination of the relationship between oil prices and the Chinese stock market.

\section{III.Model and Data Description}

\section{Model Specification and Variables}

According to stock evaluation theory, stock prices are closely associated with dividends, cash flows, net profits of firms, as well as the discount rate. Any factors that affect these variables will lead to changes in the stock price. Oil is an indispensable raw material for the production process of firms. Therefore, the change in oil prices will influence dividends, cash flows and net profit of the firm which will inevitably effect stock prices. Fama and French (1993) identify the common risk factors related to firm size and bookmarket in the returns on stocks. Therefore, these two variables have been considered as the control variables in investigating the relationship between oil and stock markets (see for example Broadstock et al., 2012). Finally, the discount rate is highly correlated with interest rates and macro-economic performance. In this paper, we do not introduce this variable directly. Instead, we introduce a market index return. The impact of macroeconomic variables on stock prices will therefore be reflected through this stock market index. Based on this analysis, we use the conventional asset pricing model to investigate 
the effect of international oil price changes on industry stock returns.

$R_{i, t}=a_{i}+\beta_{i} R_{o, t}+m_{i} R_{m i, t}+s_{i} S M B_{t}+h_{i} H M L_{t}+d_{i} D_{t}+e_{i, t}$

$i=1,2, \ldots, N, t=1,2, \ldots, T$

Where $N$ is the number of industries; $T$ is the observation for each industry; $R_{i, t}$ is the daily return for given industry $i ; R_{O, t}$ is the international oil price change; $R_{m, t}$ is the stock market return, the average return across companies traded on the Shanghai and Shenzhen stock exchanges ${ }^{2} ; S M B_{t}$ (Small Minus Big effect) and $H M L_{t}$ (High Minus Low effect) are obtained from the RESSET database to capture the firm size effect and book to market equity effect respectively; $D_{t}$, is a dummy variable equal to unity during the financial crisis ${ }^{3}$ and zero otherwise and captures differences in the relationship between oil and stock between crisis periods and non-crisis periods (Arouri, 2011).

In Eq. (1), it is assumed that each error term $e_{i}$ is unrelated across industries. This presents a problem however. Firstly, it is difficult to identify all factors affecting the industry return in the asset pricing model, which will ultimately lead to the correlation of error terms across industries in Eq. (1). Secondly, industry stock prices tend to co-move together due to contagion among industries. Therefore, the disturbances are likely to be highly correlated across industries. In this situation, a single equation regression for each industry could bias the regression results. Therefore, the seemingly unrelated regressions

\footnotetext{
${ }^{2}$ This excludes returns of companies within the industry $i$ itself, in order to avoid spurious correlation

${ }^{3}$ During the sample periods, two financial crises occurred: 2008 Global Financial Crisis (GFC) (April 2, 2007-June 1, 2009) and European Sovereign Debt Crisis (ESDC) (April 23, 2010-December 15, 2013).
} 
(SUR) is used to alleviate this problem. In this case, the SUR regression pools 29 equations together and estimates the equations simultaneously.

While there is no standard test for the specification against an alternative hypothesis of uncorrelated disturbances for the general SUR model without an assumption of normality, the Lagrange multiplier (LM) test based on the correlation matrix does have some intuitive appeal. The LM statistic is

$$
\lambda_{L M}=T \sum_{i=2}^{N} \sum_{j=1}^{i-1} r_{i j}^{2}=(T / 2)\left[\operatorname{trace}\left(R^{\prime} R\right)-N\right]
$$

Where $R$ is the sample correlation matrix of the $N$ sets of $T$ OLS residuals; and $N$ is the number of equations. The LM is distributed as $\chi^{2}\left(\frac{1}{2} N(N-1)\right)$ if the null hypothesis of diagonality is correct.

The SUR model assumes that the parameters do not vary over time. Despite this assumption, structural breaks, which can be described as the variation of parameters at dates in the sample period, can play a major role in applied time series analysis. This is particular true of China given that it has experienced many domestic oil price reforms, especially over the estimation period in question. Furthermore, international oil prices themselves are notoriously volatile. The estimation period also includes the Global Financial Crisis and European debit crisis, both of which may have led to significant breaks in the time series. With this in mind, a linear regression model that is subject to structural breaks is estimated.

In this paper, we adopt Bai and Perron (2003) (hereafter BP) model to identify multiple structural changes at unknown break dates by globally minimizing the sum of 
squared residuals. It has been well documented that the relationship between international oil prices and Chinese stocks is unstable (for example Li et al., 2012). The BP procedure is useful if this is the case as it allows us to find the optimal number of breaks implied by the data and then estimate the parameters of the processes between breaks.

The BP model assumes that there exists a maximum of $m$ breaks in the $T$ observations. The partial structural change model is,

$y_{t}=x_{t}^{\prime} \beta+z_{t}^{\prime} \delta_{j}+u_{t} \quad t=T_{j-1}+1, \ldots, T_{j}$

Where $j=1, \ldots, m+1, \quad y$ is the independent variable. $x_{t}(p \times 1)$ and $z_{t}(q \times 1)$ are the vectors of covariates. The coefficients of the former are not subjected to change and estimated using the entire sample, and those of the latter are allowed to shift across segments. Under the condition of $p=0$, Eq. (3) is transformed into a pure structural change model. The breakpoints $\left(T_{1}, \ldots, T_{m}\right)$ together with the coefficients are to be estimated simultaneously by a minimum global sum of squared residuals.

BP (2003) outlines the principle for selecting the optimal number of breakpoints. First, we should examine the UDmax statistics for the presence of at least one break. If the presence of at least one break is identified, then the number of breaks can be decided based on the condition that the tests $\operatorname{SupF}(\mathrm{I}+1 \mid \mathrm{I})$ are insignificant. Therefore, I can be defined as the optimal number of breaks.

The breaks in the time series associated with these events may make linear models inappropriate for investigating the relationship between oil prices and stock markets over time. To fully capture the nonlinearity, the relationship between oil price changes and 
Chinese stock industry returns is examined using a Markov switching (MS) model. This technique has been used to examine the relationship between oil prices and stock markets in advanced economies (Reboredo, 2010; Managi and Okimoto, 2013; Balcilar et al., 2015), but it has seldom been applied to China's stock prices. The MS model is that in Eq. (1), $e_{t} \sim N\left(0, \Omega_{S_{t}}\right)$, where $S_{t}$ is the unobserved state variable, following a firstorder Markov chain with transition probability $p_{i j}$. It is assumed that two regimes are sufficient to describe the dynamic interactions between oil and stock markets. The transition matrix can be written as;

$\left[\begin{array}{ll}p_{11} & p_{12} \\ p_{21} & p_{22}\end{array}\right], \quad \sum_{j=1}^{2} p_{i j}=1 \quad i=1,2$

The transition probability $p_{i j}$ gives the probability that state $i$ will be followed by state $j$. While often assumed to be invariant, in this paper the transition probability is allowed to vary with changes in the price of oil. This allows examination of the influence of the events in the international oil price market on the transition probability. The parameterization of the time-varying transition probability is;

$$
\begin{aligned}
& P_{11}^{t}=\operatorname{Pr}\left(S_{t}=1 \mid S_{t-1}=1\right)=\frac{e\left(\theta_{0}+\theta_{1} R_{o, t}\right)}{1+e\left(\theta_{0}+\theta_{1} R_{o, t}\right)} \\
& P_{22}^{t}=\operatorname{Pr}\left(S_{t}=1 \mid S_{t-1}=2\right)=\frac{e\left(\lambda_{0}+\lambda_{1} R_{o, t}\right)}{1+e\left(\lambda_{0}+\lambda_{1} R_{o, t}\right)}
\end{aligned}
$$

Based on Hamilton (1989), The MS model is estimated using maximum likelihood method. The likelihood ratio (LR) test is used to decide which model should be chosen: a standard linear model, a standard MS model, or a time-varying MS model. 


\section{Summary Statistics}

This study forms the industry index by categorizing the company on the basis of the relationship between oil and the characteristics of the main operating revenue of a listed company, with reference to the criteria described by the CSRC (2012). In other words, listed companies that have similar characteristics and other links with the oil industry are merged into one industry. Additionally, a new industry is formulated, "New Energy industry” which does not exist in the classification of CSRC (2012). The listed companies in this "new energy industry" include wind, solar, nuclear, geothermal energy and environmental protection companies which are otherwise scattered throughout different industries of CSRC (2012). In the sample, "ST" shares or "*ST" shares are excluded because these stocks have a daily price up/down limit of 5\% as opposed to $10 \%$ limit for ordinary shares. In addition, these shares often fluctuate more than their counterparts.

Based on the classification criteria specified above, 29 industries are constructed ${ }^{4}$. The sample covers 2570 listed companies during the sample period, accounting for 94 percent of total listed companies in China. To capture the effect of international oil prices on stock industries since the launch of oil price reform in China, the daily closing price series for listed companies from January 1st 2002 to April 30th 2015 are collected. Industry return is the average return of listed companies in a particular industry

\footnotetext{
${ }^{4}$ They are Agriculture, Chemicals, Coal, Computer, Construction, Culture, Electricity, Electronics, Finance, Food Manufacturing (Food), General Equipment (G. Equipment), Mining, Metal Product, Instrument and Meter (I. M.), New Energy, Nonmetal, Oil, Others, Paper, Pharmaceuticals, Real Estate, Retail, Rubber, Software, Special Equipment (S. Equipment), Textile, Transportation, Utilities, Vehicles.
} 
classification. The returns are calculated by differencing the natural logarithms of prices and multiplying by 100. During the sample period, there are at least 7 listed companies per industry in the sample. This ensures that any high volatility in stock prices caused by idiosyncratic information of a listed company will not dominate any dramatic change in the return for a given industry. Brent daily spot prices are used as a representative of international crude oil prices. Stock closing prices come from Wind Information Co. Ltd. The Brent Crude Oil series, denominated in dollars per barrel, was sourced from the Energy Information Administration (EIA).

Table 1 reports the descriptive statistics for daily stock returns across industries and the Brent Crude Oil series. There are 6 industries displaying negative daily returns across 29 industries, namely, Computer, Electronics, Instrument and Meter, Paper, Software, Textile. The Instrument and Meter industry has the lowest return but the highest standard deviation across all industries, while the Special Equipment industry has the highest returns with a relatively low standard deviation compared to other industries. Although the average of oil price changes is slightly greater than that of Chinese stock returns, oil prices have a higher standard deviation than most industry stocks during the sample period. This indicates a greater level of volatility in the international oil market. All the industry returns, except the New Energy industry, are negative skewed, indicating that the bulk of the returns are found to the right of the mean returns. The ADF test statistics strongly reject the null hypothesis that returns have a unit root indicating that returns are 
stationary for all industries and the Brent Crude Oil series ${ }^{5}$. Surprisingly, the correlations between each industry (excluding new energy industry) and Brent Crude Oil are found to be positive. However, the correlation is small and never exceeds 0.1.

Table 1. Descriptive Statistics for Oil and Stock markets

\begin{tabular}{|c|c|c|c|c|c|}
\hline Industry & Mean(\%) & Std.dev & Skew. & $\mathrm{ADF}$ & Corr. \\
\hline Agriculture & 0.0173 & 2.1118 & -0.5253 & $-30.72 * * *$ & 0.0407 \\
\hline Chemicals & 0.0019 & 2.0835 & -0.6450 & $-30.56 * * *$ & 0.0430 \\
\hline Coal & 0.0366 & 2.3253 & -0.1544 & $-31.44 * * *$ & 0.0904 \\
\hline Computer & -0.0108 & 2.1609 & -0.5895 & $-30.92 * * *$ & 0.0338 \\
\hline Construction & 0.0459 & 2.0639 & -0.5096 & $-30.35 * * *$ & 0.0335 \\
\hline Culture & 0.0436 & 2.0865 & -0.5425 & $-29.73 * * *$ & 0.0300 \\
\hline Electricity & 0.0421 & 1.9600 & -0.6336 & $-30.63 * * *$ & 0.0355 \\
\hline Electronics & -0.0079 & 2.0437 & -0.5990 & $-30.68 * * *$ & 0.0264 \\
\hline Finance & 0.0553 & 2.0156 & -0.3986 & $-30.31 * * *$ & 0.0445 \\
\hline Food & 0.0211 & 1.9166 & -0.4388 & $-30.89 * * *$ & 0.0124 \\
\hline G. Equipment & 0.0491 & 2.1281 & -0.6532 & $-31.01 * * *$ & 0.0263 \\
\hline Mining & 0.0161 & 2.1264 & -0.4449 & $-30.64 * * *$ & 0.0767 \\
\hline Metal Product & 0.0321 & 2.0811 & -0.7207 & $-31.95 * * *$ & 0.0296 \\
\hline I. M. & -0.0300 & 2.6085 & -1.0491 & $-30.60 * * *$ & 0.0034 \\
\hline New Energy & 0.0479 & 0.8839 & 4.0949 & $-6.70 * * *$ & -0.0207 \\
\hline Nonmetal & 0.0301 & 2.0915 & -0.5734 & $-30.54 * * *$ & 0.0421 \\
\hline Oil & 0.0432 & 1.9940 & -0.4267 & $-30.81 * * *$ & 0.0731 \\
\hline Others & 0.0110 & 2.1908 & -0.5368 & $-31.22 * * *$ & 0.0403 \\
\hline Paper & -0.0072 & 2.0386 & -0.6686 & $-31.26 * * *$ & 0.0285 \\
\hline Pharmaceuticals & 0.0062 & 1.9523 & -0.5459 & $-30.75 * * *$ & 0.0192 \\
\hline Real Estate & 0.0302 & 2.1109 & -0.5565 & $-30.29 * * *$ & 0.0388 \\
\hline Retail & 0.0136 & 1.9665 & -0.6901 & $-30.44 * * *$ & 0.0274 \\
\hline Rubber & 0.0514 & 2.0260 & -0.6020 & $-30.65 * * *$ & 0.0198 \\
\hline Software & -0.0028 & 2.1963 & -0.4612 & $-30.52 * * *$ & 0.0299 \\
\hline S. Equipment & 0.0584 & 2.0443 & -0.5510 & $-30.72 * * *$ & 0.0344 \\
\hline Textile & -0.0031 & 2.0163 & -0.7358 & $-30.34 * * *$ & 0.0317 \\
\hline Transportation & 0.0293 & 1.8908 & -0.6212 & $-30.72 * * *$ & 0.0354 \\
\hline Utilities & 0.0560 & 2.0562 & -0.6202 & $-30.66 * * *$ & 0.0328 \\
\hline Vehicle & 0.0553 & 2.0453 & -0.5952 & $-31.05^{* * *}$ & 0.0185 \\
\hline Brent & 0.0319 & 2.1157 & -0.0657 & $-31.25 * * *$ & 1.0000 \\
\hline
\end{tabular}

Notes: 'ARD’ model (autoregressive model with drift variant) with 2 lagged difference is chosen for

\footnotetext{
${ }^{5}$ Phillips-Perron (PP) test and Kwiatkowski et al. (KPSS) tests also show this result and are available upon request.
} 
the ADF test. Corr. is the correlation of industry returns with Brent oil returns. ${ }^{* * *}$ represents significance at $1 \%$ level.

\section{Empirical Results}

\section{The SUR Model}

From the OLS regression of the 29 industries, the correlation matrix of residuals for Eq. (1) can be obtained. The LM statistic is 13202 and the critical value from the chi-squared table is 454 . With the null hypothesis rejected, it is concluded that the disturbances of the industry model are not unrelated. Therefore, we can conclude that it is appropriate to use SUR to estimate Eq. (1) for the 29 industries.

Table 2 reports the results of the SUR model. Not surprisingly, the coefficients relating industry return to Brent Crude prices vary from one industry to another with coefficients range from -2.34 (Instrument and Meter industry) to 5.04 (Coal industry) ${ }^{6}$. There are 11 industries with returns that are positively influenced by international oil price changes. These are the Agriculture, Chemicals, Coal, Computer, Culture, Finance, Mining, Nonmetal, Oil, Others and Software industries. The remaining 18 industries on the other hand have a negative relationship with changes in oil prices. Of the 29 coefficients, only 11 are significant at the $5 \%$ level. Among the significant coefficients, there are 7 industries with a negative relationship (Electronics, Food Manufacturing, General Equipment, Pharmaceuticals, Retail, Rubber and Vehicle) and 4 with a positive

${ }^{6}$ For the sake of ease notation, in this paper the coefficients on oil price changes have been scaled up 100 times. 
relationship (Chemicals, Coal, Mining and Oil). The Food Manufacturing industry is most negatively affected by international oil price fluctuations among the 7 industries, with a coefficient of -2.26 . This is not particularly surprising as oil is one of the most important inputs for any manufacturing industry including food. It is logical therefore that an increase in oil prices raises costs for Food Manufacturing companies and hence lowers the stock returns of the Food Manufacturing industry. The same analysis holds true for other industries whose returns are significantly negatively affected by changes in the oil price changes.

Table 2. The Effect of Oil Price Changes on Stock Returns across Industries

\begin{tabular}{ccccc}
\hline & & & \multicolumn{2}{c}{$(2)$} \\
\cline { 1 - 2 } \cline { 4 - 5 } Industry & Brent & & Industry & Brent \\
\hline Agriculture & 0.8942 & & Nonmetal & 0.6212 \\
Chemicals & $0.7448^{* *}$ & & Oil & $3.0512^{* * *}$ \\
Coal & $5.0424^{* * *}$ & & Others & 0.7760 \\
Computer & 0.1624 & & Paper & -0.7392 \\
Construction & -0.3905 & & Pharmaceuticals & $-1.2144^{* *}$ \\
Culture & 0.1102 & & Real Estate & -0.0381 \\
Electricity & -0.5224 & & Retail & $-0.8509 * * *$ \\
Electronics & $-0.7841^{* *}$ & & Rubber & $-1.2951^{* * *}$ \\
Finance & 0.1186 & & Software & 0.0450 \\
Food & $-2.2600^{* * *}$ & & Special Equipment & -0.2262 \\
General Equipment & $-1.1269^{* * *}$ & & Textile & -0.2051 \\
Mining & $3.3498^{* * *}$ & & Transportation & -0.5561 \\
Metal Product & -0.6811 & & Utilities & -0.2255 \\
Instrument and Meter & $-2.3386^{*}$ & & Vehicle & $-1.9343^{* * *}$ \\
New Energy & -1.1458 & & & \\
\hline
\end{tabular}

Notes: ${ }^{* * *},{ }^{* *}, *$ represents significance at the $1 \%, 5 \%$ and $10 \%$ levels, respectively.

The coal industry has the highest positive response to changes in international oil prices, with a coefficient of 5.04. This result is also not a surprise given that coal is the 
traditional substitute for oil. Coal accounts for the majority (over 60\%) of China's total energy consumption issued by the National Energy Commission (NEC). An increase in the demand for coal will obviously increase the stock price of the oil industry. The domestic oil industry also has a relatively high response to changes in the international price of oil, with a coefficient of 3.05. This finding is again reasonable, in line with previous literature (El-Sharif et al., 2005; Boyer and Filion, 2007; Nandha and Faff, 2008; Broadstock et al., 2012). The results of the estimations also indicate a positive relationship between oil prices and mining industry stock returns. This is consistent with the finding of other studies such as Cong et al. (2008) and Zhang and Cong (2013). A 1\% increase in oil prices will lead to a $0.03 \%$ increase in mining industry stock returns. Again, this is not a surprising result. The operation of the mining industry is closely related to both the oil and coal industry with the mining industry providing fundamental preparation in the refining process.

The estimate of 0.74 for the chemicals industry, albeit small, may at first seem quite surprising. Oil and its by-products are one of the main resources for the chemical manufacturing industry. Therefore, a negative response to international oil price changes would be expected from the chemicals industry. There are a number of possible reasons for the counterintuitive result. Robust economic growth in China in recent years will undoubtedly increase the demand for chemicals. This growth also coincided with a period of volatility in the price of oil. Compared to the increased demand for chemicals, the increase in cost relating to higher oil prices is negligible. Rapid technological advances 
in the manufacturing of chemicals which has alleviated the pressure of price increases on raw materials, the availability of substitutes that reduces dependency on oil and its byproducts, and economies of scale in the chemicals industry may also be offered as possible explanations as to why the stock returns of the chemicals industry move positively with that of changes in the price of crude oil.

Perhaps the most interesting result is that of the electricity industry. As electricity is a substitute for oil, in theory, an increase in oil prices should benefit providers of electricity. Empirically no evidence is found of such an effect. A possible explanation for this may be advanced. In May 2005, The National Development and Reform Commission (NDRC) proposed a coal-electricity price “co-movement” mechanism which would raise electricity tariffs if coal prices rose by 5 percent or more. Fearing inflationary pressure however, policy makers have continued to control energy tariffs in recent years and the co-movement policy has never been implemented effectively. Many electricity generators are therefore unable to absorb the ensuing increases in fuel costs, resulting in huge losses. It is possible that oil price increases have not improved the expected profit of electricity generators but instead may have actually increased their losses. Other possible explanations for this result include technological progress, the prevailing application of new energy and the government's policy of weeding out what is known as "high three companies” (that is companies with high pollution, high energy consumption and high emission), all of which have reduced the demand for electricity. 


\section{Structural Breaks in the Oil Price-Stock Market Nexus}

Next we turn to the Bai and Perron (2003). In the BP model, serial correlation is allowed for in the errors and different variances of the residuals across segments ${ }^{7}$. It is assumed that Brent Crude oil prices, SMB and HML are $z_{t}$, and other variables are $x_{t}$ ${ }^{8}$. Following the BP procedure, the rationale for deciding the optimal number of breakpoints and corresponding break dates are shown in Table 3. This indicates that there exists at least one break for all industries. The majority of industries, 12 in total, have two breaks, 8 have a single break and the remaining 9 have three. The first break date occurs during the 2004 to 2006 period for 24 of the 29 industries which coincides with the launch of the share split structure reform in China. The second break date occurs between 2007 and 2009 for 12 of 21 industries, which coincides with the Global Financial Crisis. Finally, the third break date is between 2010 and 2012 for 8 of the 9 industries. This coincides with the European debt crisis debt crisis. Based on these findings, it could be argued that these three events have affected the relationship between oil price changes and Chinese industry returns.

\footnotetext{
7 The minimum ratio of each segment size to total observations to be 0.2 .

${ }^{8}$ If a rolling regression of Eq. (1) based on the rolling window $0.2 * \mathrm{~T}$ is estimated, the coefficients on the constant, oil price, SMB and HML fluctuate remarkably for the 29 industries, and the coefficients on other variables are stable.
} 
Table 3. Break Dates for 29 Industries

\begin{tabular}{cccc}
\hline Industry & Break 1 & Break 2 & Break 3 \\
\hline Agriculture & $2004 / 09 / 01^{* * *}$ & $2007 / 06 / 18^{* * *}$ & $2010 / 07 / 29^{* *}$ \\
Chemicals & $2007 / 06 / 18^{* * *}$ & & \\
Coal & $2005 / 12 / 27^{* * *}$ & $2008 / 07 / 21^{* * *}$ & $2011 / 11 / 10^{* *}$ \\
Computer & $2006 / 06 / 02^{* * *}$ & $2009 / 01 / 22^{* * *}$ & $2012 / 03 / 21^{* *}$ \\
Construction & $2006 / 12 / 11^{* * *}$ & $2012 / 03 / 23^{* * *}$ & \\
Culture & $2004 / 08 / 04^{* * *}$ & $2007 / 03 / 12^{* * *}$ & $2012 / 03 / 12^{* *}$ \\
Electricity & $2004 / 12 / 07^{* * *}$ & $2012 / 03 / 13^{* * *}$ & \\
Electronics & $2007 / 03 / 26^{* * *}$ & & \\
Finance & $2004 / 08 / 25^{* * *}$ & $2007 / 04 / 26^{* * *}$ & $2009 / 11 / 11$ \\
Food & $2007 / 01 / 25^{* * *}$ & $2010 / 12 / 31^{* * *}$ & \\
G. Equipment & $2004 / 08 / 04^{* * *}$ & $2008 / 03 / 24^{* * *}$ & \\
Mining & $2006 / 11 / 01^{* * *}$ & $2010 / 10 / 18^{* * *}$ & \\
Metal Product & $2005 / 08 / 09^{* * *}$ & $2009 / 04 / 28^{* * *}$ & \\
I. M. & $2004 / 12 / 03^{* * *}$ & & \\
New Energy & $2005 / 03 / 15^{* * *}$ & $2007 / 09 / 26^{* * *}$ & $2012 / 03 / 26^{* * *}$ \\
Nonmetal & $2006 / 06 / 05^{* * *}$ & $2012 / 03 / 23^{* * *}$ & \\
Oil & $2005 / 02 / 24^{* * *}$ & & \\
Others & $2007 / 05 / 08^{* * *}$ & $2010 / 03 / 23^{* * *}$ & \\
Paper & $2006 / 12 / 14^{* * *}$ & & $2012 / 03 / 26^{* *}$ \\
Pharmaceuticals & $2005 / 08 / 11^{* * *}$ & $2008 / 04 / 14^{* * *}$ & $2010 / 11 / 17^{* * *}$ \\
Real Estate & $2006 / 06 / 01^{* * *}$ & $2009 / 02 / 17^{* * *}$ & $2011 / 10 / 18^{* * *}$ \\
Retail & $2004 / 08 / 26^{* * *}$ & $2011 / 03 / 24^{* * *}$ & \\
Rubber & $2006 / 07 / 14^{* * *}$ & & \\
Software & $2006 / 12 / 01^{* * *}$ & $2009 / 06 / 19^{* * *}$ & \\
S. Equipment & $2006 / 01 / 11^{* * *}$ & $2011 / 12 / 16^{* * *}$ & \\
Textile & $2006 / 10 / 27^{* * *}$ & & \\
Transportation & $2005 / 08 / 15^{* * *}$ & $2009 / 07 / 06^{* * *}$ & \\
Utilities & $2010 / 06 / 01^{* * *}$ & & \\
Vehicle & $2004 / 08 / 18^{* * *}$ & $2012 / 02 / 27^{* * *}$ & \\
\hline$* * * * *$ & & \\
\hline
\end{tabular}

Notes: ${ }^{* *},{ }^{* *}$ represents significance at the $1 \%$ and $5 \%$ levels.

Next, differences are tested for across time periods by applying the BP procedure to Eq. (1). The results are presented in Table 4 and indicate that there are significant differences in the oil price coefficients across industries and across time periods. There are 15 industries whose returns are not significantly affected by oil price changes in any time period at the 5\% level: Agriculture, Computer, Construction, Culture, Electricity, 
Metal Product, Instrument and Meter, Metal Product, New Energy, Paper, Real Estate, Special Equipment, Textile, Transportation and Utilities industries. All industries whose returns are significantly influenced by oil price variations in the SUR model are still found to be significantly affected in at least one period of the BP model. The Pharmaceuticals industry is the only industry return to experience a shift in sign of the coefficient from the positive in Period 1 (1.73) to the negative in Period 2 (-3.03). The coefficients on all other industries, while different in magnitude, have a consistent sign across time periods.

Table 4. The Estimation of the BP Model across Periods for 29 Industries

\begin{tabular}{|c|c|c|c|c|}
\hline Industry & Period 1 & Period 2 & Period 3 & Period 4 \\
\hline Agriculture & 0.5558 & 1.3912 & 2.0618 & -1.3666 \\
\hline Chemicals & -0.0594 & $1.3872 * * *$ & & \\
\hline Coal & $-1.7527^{*}$ & $9.9768 * * *$ & $7.5002 * * *$ & 3.4337 \\
\hline Computer & 0.7344 & -0.1666 & -1.4495 & 2.1925 \\
\hline Construction & -0.5281 & -0.6613 & 1.9718 & \\
\hline Culture & 0.3995 & -1.7435 & 0.1874 & 1.7781 \\
\hline Electricity & 0.332 & -0.8135 & -0.5448 & \\
\hline Electronics & 0.2863 & $-1.4453 * * *$ & & \\
\hline Finance & $1.2320 * *$ & 0.1058 & 0.9023 & $-2.6971^{*}$ \\
\hline Food & $-1.4343^{*}$ & $-2.4088 * *$ & $-3.5585^{* *}$ & \\
\hline G. Equipment & 0.1555 & -1.3782 & $-1.1730 * *$ & \\
\hline Mining & $1.5002^{* *}$ & $5.1072 * * *$ & $3.2938 * *$ & \\
\hline Metal Product & -0.6106 & -0.5461 & $-1.2260^{*}$ & \\
\hline I. M. & -1.5375 & -2.5292 & & \\
\hline New Energy & -0.2057 & -4.2275 & -1.14 & -1.1696 \\
\hline Nonmetal & -0.386 & $1.6718^{* *}$ & -0.9146 & \\
\hline Oil & -0.8362 & $4.5477 * * *$ & & \\
\hline Others & 0.8523 & -0.7949 & $4.5845^{* * *}$ & \\
\hline Paper & -0.6993 & -0.7478 & & \\
\hline Pharmaceuticals & $1.7338 * * *$ & $-3.0275 * *$ & -1.721 & $-2.4539 *$ \\
\hline Real Estate & 0.0862 & -0.7394 & -0.9585 & 2.5443 \\
\hline Retail & -0.5656 & $-0.8316 * *$ & -1.2654 & \\
\hline Rubber & $-2.0099 * * *$ & -0.8058 & & \\
\hline Software & 0.8682 & -1.3413 & -1.5089 & $5.5526 * *$ \\
\hline S. Equipment & $0.9190 *$ & $-0.9456 *$ & 0.7226 & \\
\hline
\end{tabular}




\begin{tabular}{cccc} 
Textile & -0.4988 & -0.0347 & \\
Transportation & -0.3916 & $-1.0055^{*}$ & -0.1996 \\
Utilities & -0.1241 & -0.4737 & \\
Vehicle & -0.523 & $-2.7645 * * *$ & 0.7285 \\
\hline
\end{tabular}

Note: $* * *, * *, *$ represents significance at the $1 \%, 5 \%$ and $10 \%$ levels.

There are some interesting findings that merit comment. The results suggest that the effect of oil price changes has had a particularly strong effect on Coal industry returns in Period 2 and Period 3 (during the end of 2005 and the end of 2011), with an estimate of 9.98 and 7.50, respectively. The relationship between oil prices and the Finance industry, while significant prior to 2005, has become insignificant over the last ten years. This includes the period during the financial crisis. Similarly, the Rubber industry is significantly affected by oil prices before July 2006, after which the relationship does not hold. Other industries such as the Software industry and others industry have only become significantly influenced by international oil prices recently, in Period's 4 and 3 respectively. Of all 29 industries, Mining is the only industry whose returns are significantly affected by oil price changes across three time periods. Interestingly, the effect of oil price changes on Mining industry returns reaches a peak during the Global Financial Crisis. This may be due to the stimulus package implemented by the Chinese central government (\$586 billion) during Global Financial Crisis which would undoubtedly have increased the demand for crude oil and increased demand in the Mining industry. 


\section{Markov Regime Switching Model}

Next, we adopt the Markov switching model. In our estimations, the intercept and oil price changes are allowed to be regime-dependent while market returns, SMB and HML are constant under all states of economy. This condition is imposed as the latter three factors are domestic factors which it is assumed would influence industry returns in more of a consistent manner across the sample period. The variance matrix is allowed to depend on the latent regime as stock market volatility will vary significantly across regimes. The results of the LR tests can be found in Table 5. A time varying MS model was found suitable for five industries; Agriculture, General Equipment, Metal Product, Paper and Special Equipment. For the remaining 24 industries, a standard MS model is chosen. The values for sigma 1 and sigma 2, the variances of regime 1 and regime 2, are all statistically significant. This suggests that a two-regime MS model is sufficient to describe the dynamic relationship between international oil price changes and Chinese stock returns across the 29 industries. The results clearly indicate that regime 1 corresponds to the low volatility state and regime 2 to the high volatility state. The difference in volatility differs remarkably across industries with the ratio of high volatility to low volatility varying from 2.73 (Special Equipment industry) to 30.19 (New Energy industry).

The first thing to note is that industries whose stock returns are significantly affected by oil price changes in the SUR model are also significantly affected in one or both regimes of the MS model. This is with the exception of Chemicals and Pharmaceuticals industries. There are differences in the results between the SUR and the MS model 
however. For example, Metal Product, Paper and Special Equipment industries are found to be significantly affected by changes in the price of oil in the MS model, either in regime 1 or regime 2 . These three industries are not significantly affected by the same variable in the SUR model however. Of the industries that are significantly affected by changes in oil prices, four of these (Electronic, Metal Product, Paper and Rubber) are significant in regime 1. The remaining eight industries (Coal, Food Manufacturing, General Equipment, Mining, Oil, Retail, Special Equipment and Vehicle) are significant in regime 2.

Table 5. Markov Switching Model Results

\begin{tabular}{|c|c|c|c|c|c|}
\hline Industry & Regime 1 & Regime 2 & Sigma1 & Sigma 2 & LR \\
\hline Agriculture & -0.3744 & 2.9772 & $0.1982 * * *$ & $1.8182 * * *$ & $7.99 * *$ \\
\hline Chemicals & $0.6197^{*}$ & 1.0435 & $0.0740 * * *$ & $0.3519 * * *$ & 494.76*** \\
\hline Coal & -0.282 & $10.0752 * * *$ & $0.3268 * * *$ & $2.2657 * * *$ & 793.99*** \\
\hline Computer & -0.4764 & 1.7812 & $0.1418 * * *$ & $0.7350 * * *$ & $519.05^{* * *}$ \\
\hline Construction & -0.1815 & -0.7768 & $0.1572 * * *$ & $0.6412 * * *$ & $337.4 * * *$ \\
\hline Culture & -0.1706 & 0.2776 & $0.1934 * * *$ & $0.8304^{* * *}$ & $437.82 * * *$ \\
\hline Electricity & -0.0034 & -1.1535 & $0.1281^{* * *}$ & $0.9505 * * *$ & $806.05^{* * *}$ \\
\hline Electronics & $-1.0394^{* * *}$ & -0.5107 & $0.0904^{* * *}$ & $0.4088 * * *$ & $490.93 * * *$ \\
\hline Finance & -0.029 & 0.4497 & $0.1586 * * *$ & $1.0605 * * *$ & $750.26 * * *$ \\
\hline Food & $-0.8783^{*}$ & $-3.8431 * * *$ & $0.1465 * * *$ & $1.0122 * * *$ & $743 * * *$ \\
\hline G. Equipment & -0.3196 & $-1.5350 * *$ & $0.1146^{* * *}$ & $0.4068 * * *$ & $15.29 * * *$ \\
\hline Mining & -0.0233 & $5.3827 * * *$ & $0.1146 * * *$ & $0.7865 * * *$ & $675.82 * * *$ \\
\hline Metal Product & $-1.3765 * *$ & 0.119 & $0.1779 * * *$ & $0.5553 * * *$ & $5.01 *$ \\
\hline I. M. & -1.0511 & -5.2836 & $0.6877 * * *$ & $7.0050 * * *$ & $1200.57 * * *$ \\
\hline New Energy & -0.1342 & -2.2643 & $0.0578 * * *$ & $1.7441^{* * *}$ & $3750.27 * * *$ \\
\hline Nonmetal & 0.4594 & 0.8118 & $0.1080^{* * *}$ & $0.5749 * * *$ & $563.14 * * *$ \\
\hline Oil & 0.6357 & $8.4453 * * *$ & $0.2471 * * *$ & $0.9775 * * *$ & $455.34 * * *$ \\
\hline Others & -0.1961 & 1.9481 & $0.2729 * * *$ & $1.2898 * * *$ & $448.29 * * *$ \\
\hline Paper & $-1.0785^{* *}$ & 2.4996 & $0.2168 * * *$ & $1.5840 * * *$ & $85.12 * * *$ \\
\hline Pharmaceuticals & -0.3341 & $-3.2901 *$ & $0.1513^{* * *}$ & $1.1088 * * *$ & $844.05 * * *$ \\
\hline Real Estate & -0.3084 & 0.7221 & $0.1432 * * *$ & $1.1968 * * *$ & $1029.84^{* * *}$ \\
\hline Retail & -0.2615 & $-0.9946 * * *$ & $0.0502 * * *$ & $0.1869 * * *$ & $374.81 * * *$ \\
\hline Rubber & $-1.5641^{* * *}$ & -0.5036 & $0.1767 * * *$ & $0.7353 * * *$ & $541.15^{* * *}$ \\
\hline Software & -0.5007 & 1.1648 & $0.3137 * * *$ & $1.7069 * * *$ & $552.77 * * *$ \\
\hline S. Equipment & 0.3268 & $-2.8925 * * *$ & $0.1285^{* * *}$ & $0.3505 * * *$ & $41.94 * * *$ \\
\hline
\end{tabular}




\begin{tabular}{cccccc} 
Textile & -0.3312 & 0.1507 & $0.1251^{* * *}$ & $0.8301^{* * *}$ & $623.97^{* * *}$ \\
Transportation & -0.4223 & -0.5512 & $0.0766^{* * *}$ & $0.3925^{* * *}$ & $611.74^{* * *}$ \\
Utilities & -0.4042 & 0.2003 & $0.1498^{* * *}$ & $0.4956^{* * *}$ & $373.38^{* * *}$ \\
Vehicle & 0.314 & $-6.6167 * * *$ & $0.1518^{* * *}$ & $0.7081^{* * *}$ & $501.97^{* * *}$ \\
\hline
\end{tabular}

Notes: The LR statistic tests the null hypothesis of the time-varying MS model against the ordinary MS model (in bold) or the null hypothesis of the standard MS model against an ordinary linear model. ***, **, *represents significance at the $1 \%, 5 \%$ and $10 \%$ levels, respectively.

Intuitively, one would expect for the high volatility state (regime 2) to be closely associated with both financial crises and bear markets. This argument can be tested by examining the smoothed probabilities estimated by the MS model. A very simple rule is applied when relating the smoothed probabilities to a given regime. If the probability of being in one state or regime is greater than 0.5 , then that regime is present. Table 6 also presents statistics relating to the occurrence of regime 2 based on the probabilities for these 12 industries significantly affected by oil price changes in MS model. Column 1 reports that the ratio, the number of occurrences of regime 2 over the entire sample divided by sample size for the given industry, varies significantly across the 12 industries, from 3.72\% (Paper industry) to 64.85\% (Mining industry), with the average of 37.9\%. This means that regime 1 (low volatility) dominates regime 2 (high volatility) in terms of frequency across the full sample. Table 6 indicates that regime 2 most frequently occurs in during 2007, 2008, 2009 for the 12 industries. This coincides with the Global Financial Crisis. 
Table 6. Statistics for Regime 2 of MS Model

\begin{tabular}{cccc}
\hline Industry & Ratio (\%) & Periods (year) & Diff. \\
\hline Coal & 49.05 & 2008, 2007, 2009, 2013, 2014, 2010 & $0.1191^{* *}$ \\
Electronics & 39.90 & 2009, 2007, 2010, 2008, 2005, 2006 & -0.0818 \\
Food & 48.85 & 2013, 2007, 2008, 2012, 2009, 2010 & -0.0385 \\
G. Equipment & 42.97 & 2007, 2008, 2009, 2005, 2006, 2010 & 0.0746 \\
Mining & 64.85 & 2009, 2008, 2007, 2010, 2013, 2012 & -0.1011 \\
Metal Product & 47.37 & 2008, 2007, 2009, 2005, 2006, 2003 & $0.0979^{*}$ \\
Oil & 24.33 & 2007, 2008, 2009, 2012, 2006,2013 & 0.0454 \\
Paper & 3.72 & 2009, 2007, 2008, 2005, 2012, 2006 & $0.1121^{* *}$ \\
Retail & 56.83 & 2008, 2007, 2009, 2010, 2013, 2006 & 0.0703 \\
Rubber & 27.40 & 2008, 2007, 2009, 2010, 2006, 2005 & 0.0066 \\
S. Equipment & 25.20 & $2009,2008,2007,2006$ & $-0.4920^{* * *}$ \\
Vehicle & 24.36 & 2009, 2007, 2003, 2008, 2006, 2004 & $0.1221^{* *}$ \\
\hline
\end{tabular}

Notes: Periods is the years when the six largest occurrences of regime 2 take place. ${ }^{* * *}{ }^{* *}{ }^{*}$ * represents significance at the $1 \%, 5 \%$ and $10 \%$ levels, respectively.

A bear market is characterized not only by high volatility, but also by low returns. The possibility that regime 2 of the MS model is associated with a bear market is examined. This can be done by calculating the difference between the mean of industry returns in regime 2 and the mean of industry returns in regime 1 . The results of this can be found in the right hand column of Table 6. The difference and significance vary across industries. For the majority of the twelve industries, the mean of returns in regime 2 is not statistically different from that in regime 1 . For Coal, Paper and Vehicle industries, we find evidence that the mean of returns in regime 2 is higher than the one in regime 1 , while the reverse holds for Special Equipment industry. Therefore, the argument that high volatility is associated with a bear market in the Chinese stock market only holds for 3 of our industries. 


\section{Robustness test}

Two robustness tests are carried out to add reliability and credence to the findings of both the BP model and the MS model. Firstly, the robustness of the BP results is examined, by allowing the coefficient on all variables to vary across time periods. The results are slightly different from those in Section IV. For example, the optimal number of breakpoints in the robustness test for 10 industries (Chemicals, Construction, Electricity, Electronics, General Equipment, Others, Paper, Rubber, Vehicle and Oil) is one greater, and two in the case of Oil, than that in Section IV. Also, the coefficient on oil prices in this additional period is smaller than that in the preceding period, with the exception of the Chemical industry. This suggests that the relationship between oil prices and these industries stock returns reached a peak during the financial crisis but has since declined. This offers valuable implication for policy makers and investors. The actual break dates in the robustness test roughly coincides with those in the main body. Overall, it can be said that the findings of the robustness test are fairly consistent with that of BP model in Section IV.

The second robustness test relates to the Markov switching model. Unlike the model in the main body, the coefficients on all variables are allowed to vary with regimes. The results for all industries are in accordance with those in Section IV. This is with the exception of the Special Equipment industry which is found to be highly significant in the second regime in Section IV but is insignificant in the second regime of the robustness 
test. The coefficient relating the Special Equipment industry to oil price changes in the robustness test is consistent with that of both the SUR model and BP model however. Overall, it would appear that the results are rather robust, lending support to the findings in Section IV of the paper.

\section{Conclusions}

It is well documented that the relationship between oil prices and stock markets differs across industries. This paper investigates the effect of oil price changes on Chinese stock market returns across 29 industries first using a SUR model. The results show that four industry returns (Coal, Chemicals, Mining and Oil) are positively affected by oil price changes while seven industry returns (Electronics, Food Manufacturing, General Equipment, Pharmaceuticals, Retail, Rubber and Vehicle) are found to be negatively influenced by oil price changes. The effect of oil price changes on industry returns using a breakpoints model is also estimated. The results confirm that the effect varies over time and that the breakpoints differs across 29 industries. While it is extremely difficult to derive a uniform pattern across 29 industries from these estimations, the results show that the effect of oil price changes on industry returns has intensified since 2004 for most industries. Finally, a Markov switching model is applied to investigate the relationship between oil prices and stock market returns under different regimes. This nonlinear 
technique allows us to examine asymmetry in the relationship between oil prices and Chinese stock returns across industries. The results suggest that one of these regimes (Regime 2) is associated with high volatility and that stock returns are more responsive to changes in oil prices in this regime. Regime 2 most frequently occurs during financial crisis, but is not associated with a Chinese bear market for most industries.

The empirical findings of this paper have important implications for investors and policymakers alike. For investors, the results provide an understanding of the relationship between Chinese stocks and international oil price changes, particularly with regard to variations across industries and time periods, as well as with regard to the increase or decrease of international oil prices. Firstly, for the purposes of diversification, investors should choose to hold stocks whose returns have no significant relationship with oil prices. Secondly, our results suggest that when the price of international oil increases, investors should hold industry stocks whose returns are positively correlated with changes in oil price and short industry stocks with returns that are negatively correlated with changes in oil price. Conversely, the reverse of this strategy should be adopted in the presence of decreases in the international price of oil. The results also provide useful recommendations for policymakers. The Chinese government should take effective measures to fight the negative effects of international oil price shocks on domestic stock markets as the relationship between oil and stock markets strengthens, particularly during periods of financial turbulence. 


\section{References}

Akoum, I., M. Graham, J. Kivihaho and M. Omran, 2012, "Co-movement of oil and stock prices in the GCC region: A wavelet analysis,” Quarterly Review of Economics \& Finance, Vol. 52, No. 4, pp. 385-394.

Arouri, M. E. H., 2011, "Does crude oil move stock markets in Europe? A sector investigation,” Economic Modelling, Vol. 28, No. 4, pp. 1716-1725.

Arouri, M. E. H., and C. Rault, 2012, "Oil prices and stock markets in GCC countries: Empirical evidence from panel analysis," International Journal of Finance \& Economics, Vol. 17, No. 3, pp. 242-253.

Bai, J. and P. Perron, 2003, “Computation and analysis of multiple structural change models,” Journal of Applied Econometrics, Vol. 18, No. 1, pp. 1-22.

Balcilar, M., R. Gupta and S. M. Miller, 2015, "Regime switching model of US crude oil and stock market prices: 1859 to 2013,” Energy Economics, Vol. 49, pp. 317-327.

Boyer, M. M. and D. Filion, 2007, "Common and fundamental factors in stock returns of Canadian oil and gas companies,” Energy Economics, Vol. 29, No. 3, pp. 428-453.

Broadstock, D. C., H. Cao and D. Zhang, 2012, "Oil shocks and their impact on energy related stocks in China,” Energy Economics, Vol. 34, No. 6, pp. 1888-1895.

Cong, R. G., Y. M. Wei, J. L. Jiao and Y. Fan, 2008, "Relationships between oil price shocks and stock market: An empirical analysis from China,” Energy Policy, Vol. 36, No. 9, pp. 3544-3553.

El-Sharif, I., D. Brown, B. Burton, B. Nixon and A. Russel, 2005, "Evidence on the nature and extent of the relationship between oil prices and equity values in the UK," Energy Economics, Vol. 27, No. 6, pp. 819-830.

Fama, E. F. and K. R. French, 1993, “Common risk factors in the returns on stocks and bonds,” Journal of Financial Economics, Vol. 33, No. 1, pp. 3-56.

Filis, G., S. Degiannakis and C. Floros, 2011, "Dynamic correlation between stock market and oil prices: The case of oil-importing and oil-exporting countries," International Review of Financial Analysis, Vol. 20, No. 3, pp. 152-164.

Gogineni, S., 2010, “Oil and the stock market: An industry level analysis,” Financial Review, Vol. 45, No. 4, pp. 995-1010.

Hamilton, J. D., 1989, “A new approach to the economic analysis of nonstationary time series and the business cycle,” Econometrica, Vol. 57, No. 2, pp. 357-384.

Hammoudeh, S. and K. Choi, 2006, "Behavior of GCC stock markets and impacts of US oil and financial markets,” Research in International Business and Finance, Vol. 20, No. 1, pp. 22-44.

Henriques, I. and P. Sadorsky, 2008, “Oil prices and the stock prices of alternative energy companies,” Energy Economics, Vol. 30, No. 3, pp. 998-1010.

Katircioglu, S. T., K. Sertoglu, M. Candemir and M. Mercan, 2015, "Oil price movements and macroeconomic performance: Evidence from twenty-six OECD countries,” Renewable and Sustainable Energy Reviews, Vol. 44, pp. 257-270.

Kumar, S., S. Managi and A. Matsuda, 2012, "Stock prices of clean energy firms, oil and carbon markets: A vector autoregressive analysis,” Energy Economics, Vol. 34, No. 1, pp. 215-226. 
Li, S. F., H. M. Zhu and K. Yu, 2012, "Oil prices and stock market in China: A sector analysis using panel cointegration with multiple breaks,” Energy Economics, Vol. 34, No. 6, pp. 1951-1958.

Managi, S. and T. Okimoto, 2013, "Does the price of oil interact with clean energy prices in the stock market?,” Japan and the World Economy, Vol. 27, pp. 1-9.

Nandha, M. and R. Brooks, 2009, "Oil prices and transport sector returns: an international analysis," Review of Quantitative Finance and Accounting, Vol. 33, No. 4, pp. 393-409.

Nandha, M. and R. Faff, 2008, "Does oil move equity prices? A global view," Energy Economics, Vol. 30, No. 3, pp. 986-997.

Park, J. and R. A. Ratti, 2008, "Oil price shocks and stock markets in the US and 13 European countries,” Energy Economics, Vol. 30, No. 5, pp. 2587-2608.

Reboredo, J. C., 2010, "Nonlinear effects of oil shocks on stock returns: A Markov-switching approach,” Applied Economics, Vol. 42, No. 29, pp. 3735-3744.

Sadorsky, P., 1999, “Oil price shocks and stock market activity,” Energy Economics, Vol. 21, No. 5, pp. 449-469.

Sukcharoen, K., T. Zohrabyan, D. Leatham and X. Wu, 2014, "Interdependence of oil prices and stock market indices: A copula approach,” Energy Economics, Vol. 44, pp. 331-339. 